\title{
Re-constraining massive pied-piping: An argument for non-interrogative CPs
}

\author{
Daniel G. Amy*
}

\begin{abstract}
Unlike traditional $w h$-movement and obligatory pied-piping, massive pied-piping is restricted in the types of clauses in which it may occur. Heck $(2004,2008)$ argues that massive pied-piping constructions are restricted to nonsubordinate clauses in English. This paper (i) investigates the availability of massive pied-piping of DPs in complements of know and surprise-type predicates; (ii) proposes a revised generalization on massive pied-piping that restricts the construction to non-interrogative clauses; and (iii) proposes a hybrid analysis that combines Cable's (2010) Q-movement analysis with Den Dikken's (2003) two-stage whmovement operation, thus accounting for the wider set of environments covered by the revised generalization on massive pied-piping in English.
\end{abstract}

Keywords. syntax; wh-movement; pied-piping; QP; English

1. Introduction. Since it was first introduced by Ross (1967, 1986), pied-piping has been a problem for generative grammars. In addition to needing an explanation regarding how a larger constituent containing a $w h$-phrase can move, the range of sizes and shapes that this larger constituent can take also needs to be constrained. This paper focuses on the "massive piedpiping' (Heck 2004, 2008) of a larger DP, like those originally introduced by Ross, presented here in (1), and the environments in which this marked construction may occur.

\section{(1) Massive pied-piping of a DP (Ross 1967: 198)}

a. Reports [DP the covers of which] the government prescribes the height of the lettering on $t$ almost always put me to sleep.

b. Reports [DP the lettering on the covers of which] the government prescribes the height of $t$ are a shocking waste of public funds.

c. Reports [DP the height of the lettering on the covers of which] the government prescribes $t$ should be abolished.

While traditional wh-movement, (2), and obligatory pied-piping, (3), are rather unfettered in the types of clauses in which they may appear, massive pied-piping constructions like those above have narrower distribution of environments where they may occur.

(2) Simple wh-movement (Ross 1967: 197)

Reports [DP which] the government prescribes the height of the lettering on the covers of $t$ are invariably boring.

(3) Obligatory pied-piping (Ross 1967: 208) The boy [DP whose guardian's employer] we elected $t$ president ratted on us.

This paper presents evidence in the form of massive pied-piping in complement clauses of verbs like know and surprise, which seemingly violates Heck's (2004; 2008) generalization on massive pied-piping. Based on this new evidence and other environments where massive pied-piping may freely or marginally occur, I propose an alternate generalization in which this marked construction is restricted to non-interrogative clauses and further propose the merging

\footnotetext{
* Author: Daniel G. Amy, University of Texas at Arlington (daniel.amy@ mavs.uta.edu).
} 
of theoretical frameworks proposed by Cable (2010), Richards (2017), and Den Dikken (2003) to account for the wider set of environments where massive pied-piping may occur.

1.1. THE PROBLEM OF MASSIVE PIED-PIPING. Unlike simple $w h$-movement and obligatory pied-piping, massive pied-piping of a larger DP is problematic for two reasons. First, the massive pied-piping of a larger DP is optional, as shown by the contrast of the presence of massive pied-piping in (1) and the lack thereof in (2), where only simple wh-movement occurs. This contrasts with the obligatory nature of the pied-piping in (3) - which is driven by the Left Branch Condition (Ross 1967, 1986).

The second problem with massive pied-piping, and the one with which this paper is primarily concerned, relates to the narrower set of environments in which massive pied-piping may occur, when compared to simple wh-movement and obligatory pied-piping. The restriction on massive pied-piping can most easily be seen between the contrast between embedded clause questions and matrix questions, given in (4). It should be noted, however, that the matrix clause question in $(4 \mathrm{~b})$ requires an echo interpretation, indicated by the small capital notation on which.

(4) Matrix/embedded clause asymmetry: massive pied-piping (Heck 2008: 169)

a. *Horace asked [DP pictures of which family] $t$ were on sale.

b. [DP Pictures of WHICH family] are $t$ on sale?

The clear ungrammaticality of the massive pied-piping in embedded contexts is contrasted by the complete grammaticality of simple wh-movement and that of obligatory pied-piping, as shown in (5) and (6), respectively. While the matrix clause constructions in (5b) and (6b) are also grammatical, they do not require an echo question interpretation like (4b).

(5) No matrix/embedded clause asymmetry: wh-phrasal movement

a. Horace asked [DP which pictures] $t$ were on sale.

b. [DP Which pictures] are $t$ on sale?

(6) No matrix/embedded clause asymmetry: obligatory pied-piping

a. Horace asked [DP which family's pictures] $t$ were on sale.

b. [DP Which family's pictures] are $t$ on sale?

If massive pied-piping cannot occur in all of the same environments that traditional whmovement and obligatory pied-piping can, there must be some formal mechanisms that disallow the more marked construction from occuring in embedded clause questions.

1.2. GENERALIZATION ON MASSIVE PIED-PIPING. Heck $(2004,2008)$ draws on the ungrammaticality of massive pied-piping in embedded clause questions in (4) and a general dispreference for allowing massive pied-piping in restrictive relative clauses to propose a non-subordinated restriction on massive pied-piping. Heck's states this restriction as the generalization on massive pied-piping, given in (7).

(7) Generalization on massive pied-piping (Heck 2008: 160)

Massive pied-piping is only possible if the $\mathrm{CP}$ whose specifier is the target of $w h$-movement is not subordinated.

While this generalization is rather straight forward in how it applies to the embedded versus main clause asymmetry, the restricted non-restricted asymmetry follows from the additional 
assumption that non-restrictive relative clauses behave as if they are non-subordinated (see Emonds 1979).

1.3. PROBLEMS FOR THE GENERALIZATION. While other contemporary analyses of pied-piping agree with Heck on restricting massive pied-piping to non-subordinated clauses (see Cable 2010; Richards 2017), there is some disagreement in the literature surrounding the availability of massive pied-piping in restrictive relative clauses. Notably, in his original discussion of massive pied-piping, Ross (1967) presents his examples of massive pied-piping of a DP in restrictive relative clauses. Furthermore, descriptive grammars of English by Stockwell, Schacter \& Partee (1973) and Huddleston \& Pullum (2002) treat the construction as available in restrictive relative clauses as well.

If speakers are cable of violating the generalization on massive pied-piping in certain cases, specifically restrictive relative clause constructions, it should likewise be possible for the same speakers to violate this restriction across the board, which should thereby allow massive pied-piping in embedded clause contexts introduced by verbs like wonder. However, this does not appear to fully be the case. In the section that follows, I present evidence that some speakers of English allow massive pied-piping a subset of complement - and therefore embedded - clauses, so long as the complement clause is the complement of a verb that behaves like know.

2. Evidence from complement clauses. While the massive pied-piping of a larger DP is categorically bad in embedded contexts that serve as the complement to verbs like wonder, this ungrammaticality does not extend equally to the complements of CP-embedding verbs. As shown in (8a) below, some speakers allow the massive pied-piping of a DP in complements of know. While the grammaticality of massive pied-piping of DPs in complements of know in English is not universally accepted, with judgments ranging from completely unacceptable to marked to near impeccable, massive pied-piping of the DP is reportedly ungrammatical across speakers in the complement of wonder in (8b).

(8) Embedded clause asymmetry: know and wonder

a. \%I know [DP the poster of which pop star] Mary hung $t$ in her office.

b. *I wonder [DP the poster of which pop star] Mary hung $t$ in her office.

While constructions like (8a) are marked for speakers who do allow the massive piedpiping of the DP, this markedness can usually be obviated when it is preceded by a supportive context, as shown in (9). While a supportive context alleviates the markedness of massive pied-piping in the complement of know in (9a), this does not apply to massive pied-piping in the complement of wonder in $(9 b)$.

(9) Speaker A: Did you hear? Mary hung up a poster of some pop star in her office.

a. Speaker B: I know [DP the poster of which pop star] she hung up $t$. (I was in there this morning.)

b. Speaker B: *I wonder [DP the poster of which pop star] she hung up $t$.

If massive pied-piping is truly restricted to non-subordinated clauses as Heck $(2004,2008)$ originally argues, the massive pied-piping of a DP in complements of know is problematic. A potential counterargument might be that the construction in (8a) contains a DP complement to know, rather than a CP complement, as know can take DP complements, as shown in (10). 
a. I know [DP the best recipe for chili].

b. I know [DP a/this great recipe for chili].

I would argue against a DP-complement analysis for these apparent cases of massive piedpiping of a DP in complement clause, on the basis of a number of asymmetries. While DP complements of know can appear with the variety of determiners shown above, this does not appear possible in cases containing apparent massive pied-piping, as shown in (11).

(11) Lack of determiner variety with apparent massive pied-piping

I know [DP a/this poster of which pop star] Mary hung $t$ in her office.

Complements that are clearly DPs can notably take both the definite determiner and the indefinite determiner, or the demonstrative determiner. This distribution of determiners is not possible for the case of apparent massive pied-piping in (11), as both the indefinte and demonstrative determiners result in ungrammaticality. Only the definite determiner present in (8a) is grammatical. This asymmetry suggests that something greater is at play.

In addition to restrictions on the determiner in these apparent cases of massive pied-piping in complement clauses, similar constructions are also possible in the complements of predicates that allow CP complements and a narrower set of DP complements. In addition to know, massive pied-piping of a DP is also possible for some speakers in complements of tell, as shown in (12a). As with the know/wonder asymmetry, tell's converse ask in (12b), does not allow the massive pied-piping construction.

(12) Embedded clause asymmetry: tell and ask

a. \%John told Sue [DP the poster of which pop star] Mary hung up $t$ in her office.

b. \#John asked Sue [DP the poster of which pop star] Mary hung up $t$ in her office.

Unlike know, which s-selects for a wide variety of DP complements, tell s-selects for a much smaller set of potential complements, notably ones that represent some type of communication, as given in (13), and disallows DP complements that are not communicative in nature.

S-selection of tell

a. John told Mary \{the answer to the question / a funny joke / a scary story\}.

b. \#John told Mary\{the painting of Washington / a guy who knows a guy / Bob\}.

When the tell construction in (12a) is simplified to a DP in (14), the result is semantically odd, which does not occur in (12a), when the complement of tell appears to contain massive pied-piping.

(14) \#John told Sue [DP the poster].

Lastly, the possibility of massive pied-piping in complement clauses is also possible in complements of predicates like surprise, as shown in (15a). Unlike both know and tell, surprise cannot take a DP complement, as shown in (15b).

$\mathrm{C}$-selection of surprise

a. \% $\mathrm{It}_{\mathrm{EXP}}$ 's surprising [DP the poster of which pop star] Mary hung $t$ in her office.

b. * $\mathrm{It}_{\mathrm{EXP}}$ 's surprising [DP the poster]. 
Based on these three diagnostics, I believe that a $\mathrm{CP}$-complement analysis is superior to a DP analysis for constructions presented in (8a), (12a), and (15a). Such an analysis, however, is problematic for Heck's $(2004 ; 2008)$ generalization on massive pied-piping, as these environments are clearly embedded.

3. Revising the generalization. The environments in which massive pied-piping are grammatical and ungrammatical, along with the non-subordinated status of the CP hosting the movement, are given in Table 1. While the generalization on massive pied-piping predicts the availability of massive pied-piping in echo questions, non-restrictive relative clauses, and complements of verbs like wonder, it cannot fully explain why true question interpretations are disallowed in matrix clause questions, nor why some speakers allow massive pied-piping in restrictive relative clauses or complement clauses to verbs like know.

\begin{tabular}{lcc} 
& Grammaticality & Non-subordinated \\
\hline Matrix clauses & & Yes \\
- True questions & $*$ & Yes \\
- Echo questions & - & \\
Relative clauses & & Yes \\
- Non-restrictive & - & No \\
- Restrictive & $\%$ & \\
Complement clauses & & No \\
- know-type & $\%$ & No \\
- wonder-type & $*$ & \\
\hline
\end{tabular}

Table 1: Grammaticality of massive pied-piping by clause type

3.1 A NOn-Interrogative Restriction. While all of the environments listed in Table 1 are environments that allow $w h$-movement and can grammatically host obligatory pied-piping, I note that the environments in which massive pied-piping is ungrammatical share a common feature: true interrogativity. Therefore, I propose that the environments where massive piedpiping is allowed (even where only by a subset of speakers) are not truly interrogative, despite being able to host wh-movement. Further, I propose that the generalization on massive piedpiping in (7) should be revised to focus on the non-interrogative nature of the CPs capable of hosting massive pied-piping, rather than the clause's non-subordinated status. This revision is formalized in (16).

(16) Revised generalization on massive pied-piping

Massive pied-piping is only possible if the $\mathrm{CP}$ whose specifier is the target of $w h$-movement is not interrogative.

3.2. PARALlELS WITH OTHER SYNTACTIC/SEMANTIC RESTRICTIONS. While it may seem counterintuitive to propose that massive pied-piping be restricted to non-interrogative clauses, there are other syntactic and semantic phenomenon upon which this distinction plays an important role. One such case is with wh- exclamatives, as discussed by Grimshaw (1979). As shown in (17a), matrix clause $w h$ - exclamatives result in $w h$-movement but do not allow subject-auxiliary inversion, which is required for true matrix clause interrogatives, as shown in (17b). 
(17) Matrix wh-exclamtives/wh-interrogatives (Grimshaw 1979: 281)

a. What a fool he is $t$ !

b. *What a fool is he $t$ ?

In addition to the lack of subject-auxiliary inversion, Grimshaw (1979) notes that fronting of a wh- exclamative is possible in complements of surprise and know-type verbs, but not wonder-types, as shown in (18). Grimshaw also notes that unlike know and wonder-type verbs, surprise-type verbs may not take CP complements headed by whether, as shown in (19). If the presence of whether is an indication of interrogativity, this suggests that complements of surprise-type verbs cannot be interrogative.

(18) Embedded wh-exclamatives (Grimshaw 1979: 281)

a. I'm surprised at [DPWhat a large house] he lives in $t$.

b. John knows [DP what a fool] he is $t$.

c. *I wonder [DPWhat a large house] he lives in $t$.

(19) Embedded clauses headed by whether (Grimshaw 1979: 281)

a. *I was surprised at whether he lived in a large house.

b. John knows whether he is a fool.

c. I wonder whether he lives in a large house.

Even though know-type predicates can take complements headed by whether, the availability of wh-exclamatives in the complements of know-type predicates suggests that not all instances of wh-movement in complements of know need to occur within an interrogative.

Looking at the distribution of massive pied-piping from a different angle, it shows a polar opposite behavior to the distribution of aggressively non-D-linked wh-the-hell constructions in embedded clauses that discussed by Den Dikken \& Giannakidou (2002), presented here in (20). While the wh-the-hell construction is licensed in the complement of wonder, it is disallowed in complement clauses of know. Den Dikken \& Giannakidou note that matrix clause negation can obviate the ungrammaticality in (20b), but this is due to negation licensing the polarity item, who the hell.

(20) Licensing of wh-the-hell (Den Dikken \& Giannakidou 2002: 34, 45)

a. I wonder [DP who the hell] $t$ bought that book].

b. *I know [DP who the hell] $t$ bought that book].

While massive pied-piping appears to be ill-behaved when compared to simple wh-movement and its well-behaved obligatory pied-piping kin, it does appear to pattern alongside and in direct inverse to, other varieties of wh-movement that have restrictions on where they may occur.

4. Explaining the asymmetries. To formally account for the revised generalization on massive pied-piping, I propose that two existing frameworks be combined, namely those proposed by Cable (2010) and Den Dikken (2003). While these two analyses lack the ability to account for the revised generalization on their own, when combined, they allow for the potential of massive pied-piping in non-interrogative clauses, while disallowing it in interrogative clauses.

4.1. EXISTING FRAMEWORKS. Basing his analysis on data from Tlingit, Cable (2010) proposes that all wh-movement is the result of Q-movement, and that the size and shape of a grammatical QP can be constrained by the QP Intervention Condition. Cable's analysis, which 
has been further modified by Richards (2017) under a Contiguity Theory (Richards 2016) framework, proposes that the movement of the QP is motivated by the presence of a feature [Q] on C and the head of the QP. As shown in the (21), Q-movement happens as a result of the agreement between the two heads bearing the feature [Q]. Wh-agreement is still present in Cable's analysis, but he argues that this agreement relationship is between the Q-particle and the wh-word, which is c-commanded by the Q-particle in side of the QP itself.

Q-movement Analysis (Cable 2010: 141)

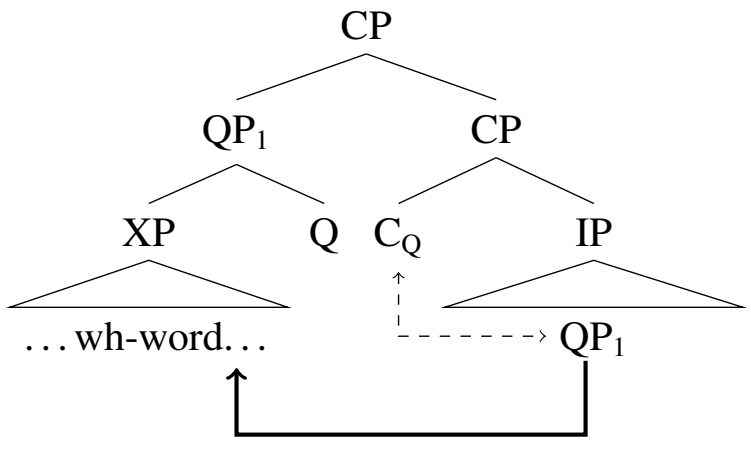

To account for the unavailability of massive pied-piping in embedded contexts in English, Cable (2010) argues there are two different Q-particles in English: one with a WH feature and one without. The former is used in subordinated contexts, while the latter is used in nonsubordinated contexts. While this allows massive pied-piping in non-subordinated CPs and disallows it in subordinated CPs, this is somewhat of a stipulative solution, as it is unclear how the Q-particle recognizes the type of CP under which it moves. Given the distribution of environments in which massive pied-piping appears possible in English (provided in Table 1), Cable's analysis of massive pied-piping is insufficient on its own: it can account for the moving of the larger constituent, but not the wider set of environments of where the movement can occur.

The second framework that can be used to explain when massive pied-piping of a DP is possible is the framework proposed by Den Dikken (2003). While Den Dikken is not concerned with pied-piping constructions, he is interested in differences between $w h$-movement in truly interrogative matrix clause questions, echo questions, and embedded clause asymmetries. In his analysis of wh-movement, Den Dikken argues for a two-stage wh-movement process. Under this process, wh-movement occurs first as Focus-movement, motivated by a feature [FOC] on the Focus head, and then a second $w h$-movement occurs as the result of the feature [WH] on a higher $\mathrm{C}$ head.

Den Dikken (2003) argues that while both interrogative and echo questions employ whmovement as a result of Focus-agreement, he argues that the feature [WH] is present on the higher $\mathrm{C}$ head for interrogative questions, but not on that of echo questions. Under this analysis, wh-agreement only occurs in interrogative questions and not echo questions. The lack of the feature $[\mathrm{WH}]$ in echo questions can thus explain why the wh-phrase may appear in situ in echo questions. If this were to apply in conjunction with Q-movement, it could be possible to account for the distribution of massive pied-piping.

While Den Dikken's (2003) analysis can account for a separate asymmetry shown between truly interrogative matrix clause questions and echo questions, his analysis is incapable 
of dealing with pied-piping constructions of either the obligatory or optional massive piedpiping varieties. However, by merging Den Dikken's analysis with that of Cable (2010) and subsequently Richards (2017), I propose that the greater distribution of environments in which massive pied-piping may occur can be accounted for.

4.2. APPLYING THE FRAMEWORKS. If we assume that $w h$-movement, widely construed, is the result of Q-movement, we can account for the size and shape of the constituent being piedpiped based on Cable's (2010) QP intervention condition. (The QP Intervention Condition also, by design, forces the pied-piping of the larger DP in obligatory pied-piping by a possessor.) Furthermore, if we assume that Q-movement is the result of Focus-movement a la Den Dikken (2003), we are presented with a movement structure that still allows for wh-agreement within the $\mathrm{CP}$ that hosts the pied-piping.

As a welcome side effect, the feature $[\mathrm{WH}]$ is extracted from the Q-particle and transplanted it to the higher $\mathrm{C}$ head. This, in turn, gives the CP hosting the pied-piping greater control on the types of pied-piping constructions that it would allow, rather than stipulating two different Q-particles (one with a feature [WH] and another without). Following premises of Contiguity Theory (Richards 2016), specifically the notion of contiguity prominence, the availability of massive pied-piping in some, but not all, contexts could therefore be boiled down to whether CP hosting the movement has a head bearing the feature [WH].

If we assume that the feature $[\mathrm{WH}]$ is available for the head of a $\mathrm{CP}$ that bears interrogative force - namely matrix clause non-echo questions and complements of wonder-type verbs - we should expect wh-agreement to occur and that this agreement should not give rise to problems when simple wh-movement or obligatory pied-piping occurs. As shown in the derivation in (22), this is the case. Following Den Dikken (2003), the feature [FOC] is initiated by the Focus head. The goal, now present on the Q-particle, projects to the larger QP containing the wh-phrase. In order to satisfy the Locality of Agree, the QP moves to Spec,FocP, where the feature $[\mathrm{FOC}]$ is contiguity prominent in the QP.

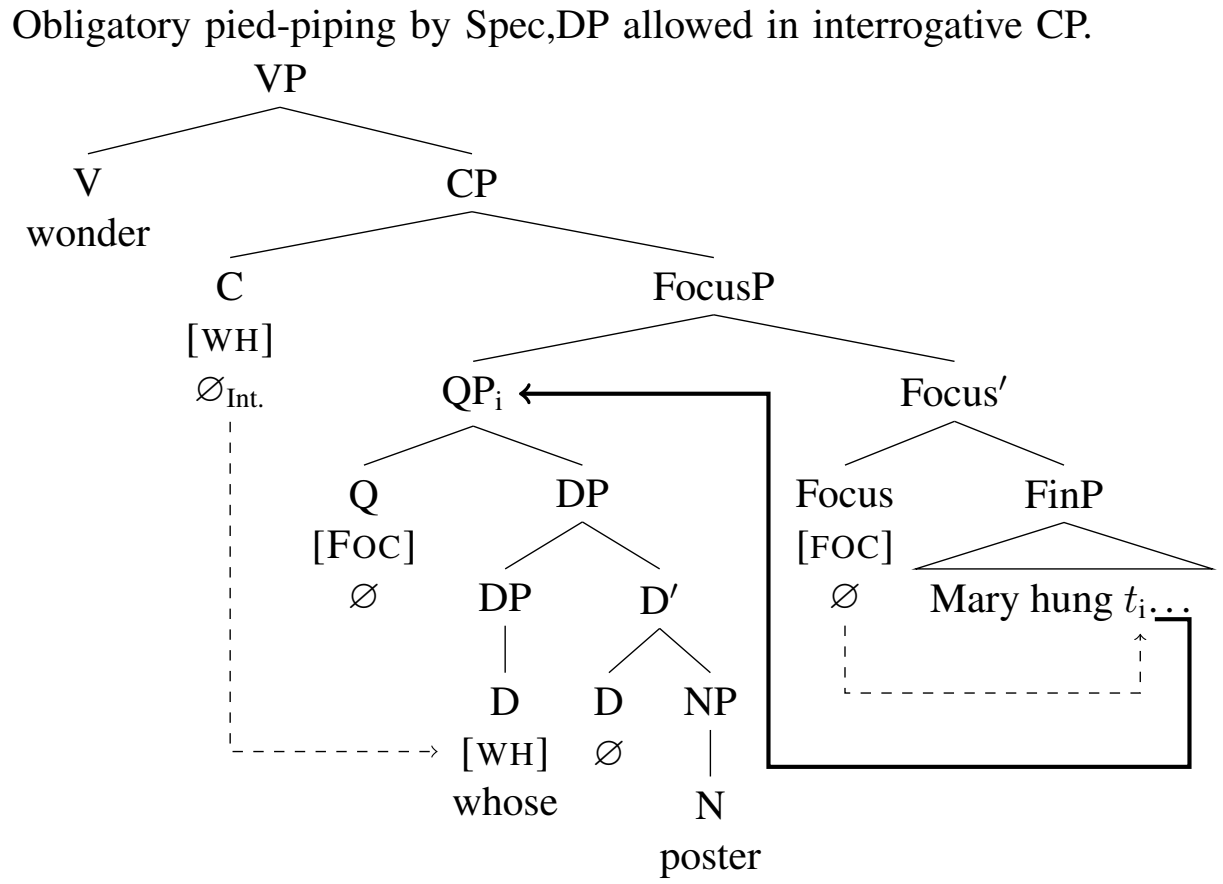


Now, when the feature [WH] on $\mathrm{C}$ probes, it finds its goal on the wh-word that serves as the head of the wh-phrase. Because there is no intervening phonological content between this wh-probe and its goal, no movement is required to satisfy the Locality of Agree, as the goal is in a contiguity prominent position due to the lack of intervening material. While this derivation presents this agreement relationship for the more complex case of obligatory pied-piping, instances of simpler wh-movement, wherein only the wh-phrase is moved, would follow the same process, albeit with a simpler structure within the moved QP.

In the event of massive pied-piping, the derivation is slightly different as shown in (23). The massive pied-piping of the larger DP to Spec,FocP is still motived by Focus-movement. However, when the feature $[\mathrm{WH}]$ on the higher $\mathrm{C}$ head probes, it finds its goal deeply along the right edge of the QP. Due to the intervening phonological content, the $[\mathrm{WH}]$ goal is not contiguity prominent within FocP. Since the movement of the QP effectively freezes it (Corver 2017), extraction of the wh-phrase to Spec,CP is impossible as well. With no way for the locality of Agree to be satisfied following Richards $(2016,2017)$, the derivation crashes.

Massive pied-piping disallowed in interrogative $\mathrm{CP}$

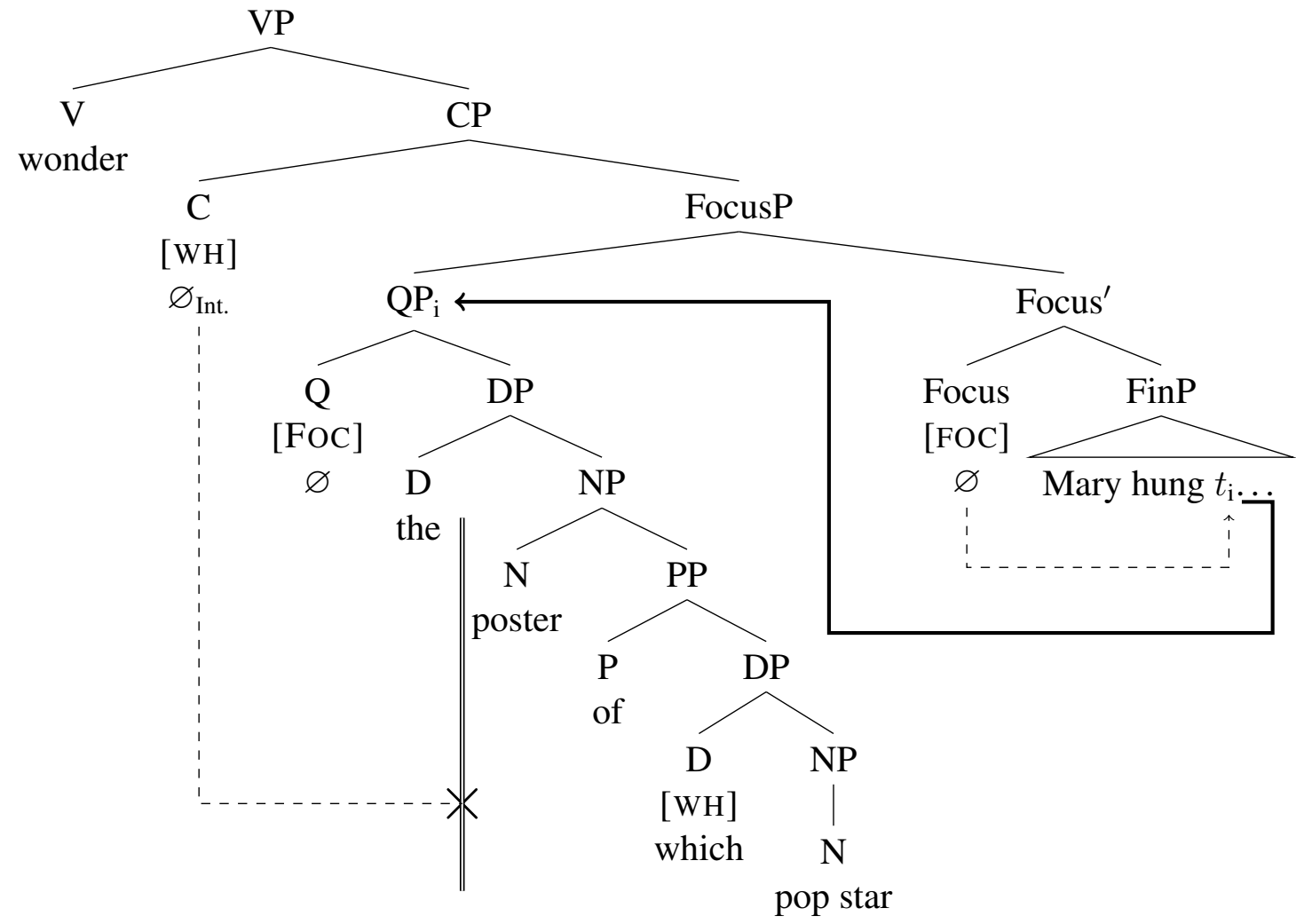

If the head of the CP complements of know and surprise lack the feature [WH] due their noninterrogative nature, this would result in yet another derivation. In this new derivation, presented in (24), massive pied-piping again results from Focus-movement, and the QP is moved to Spec,FocP. Unlike the derivation presented in (23), C in (24) lacks the feature [WH]. Without this feature to serve as a probe, no wh-agreement relationship is initiated. As such, the derivation is allowed to continue. 
(24) Massive pied-piping allowed in non-interrogative CP

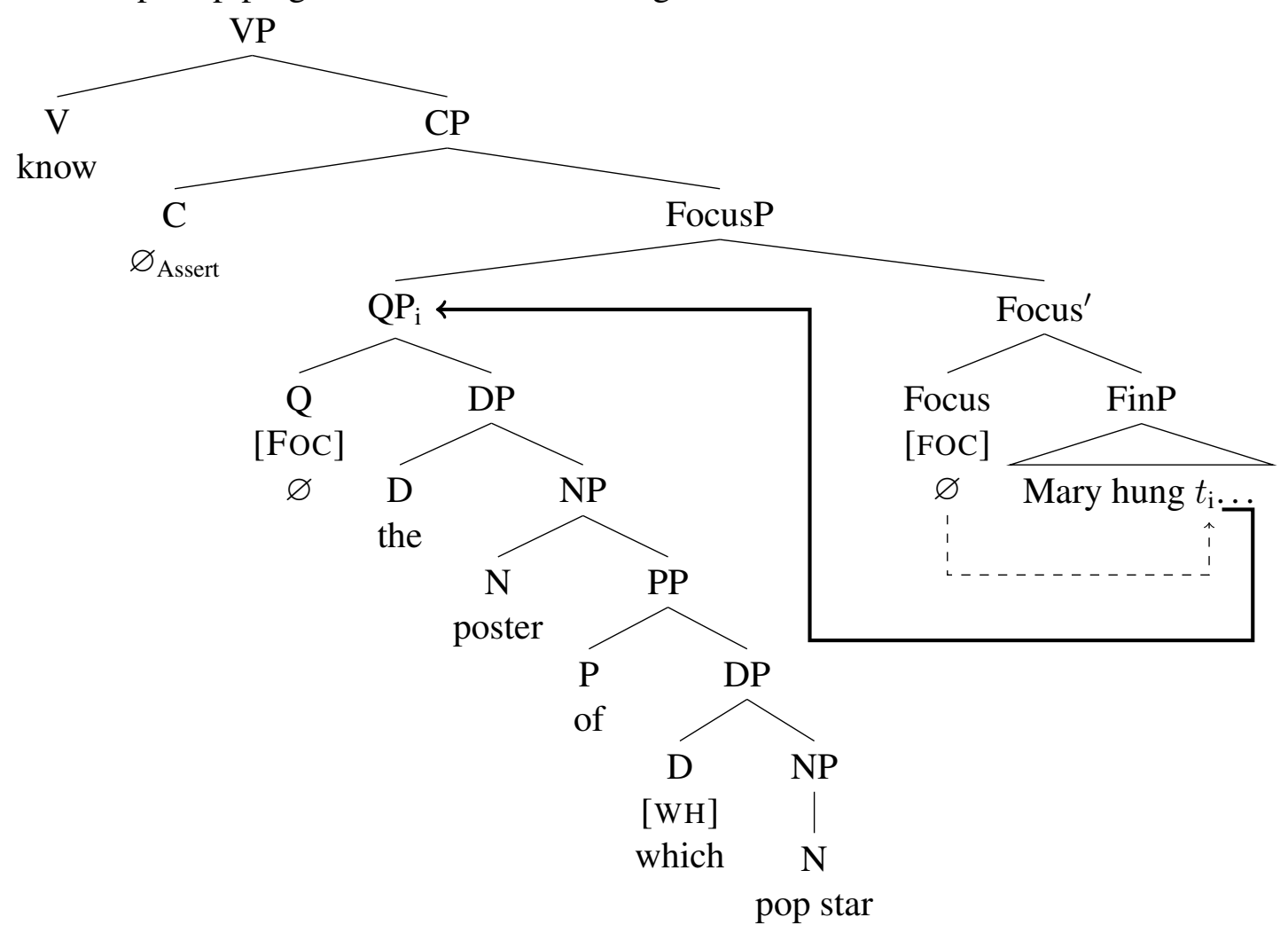

While the derivations above provide an account for the availability of massive pied-piping in complements of know and surprise-type predicates and its unavailability in complements of wonder-type predicates, this analysis can be further applied to matrix clauses. While whinterrogative questions would require the presence of the feature $[\mathrm{WH}]$ and subsequently lead to a crash in the derivation should massive pied-piping occur as outline by the derivation in (23), Den Dikken's (2003) argument that echo questions lack such a feature would allow derivations with massive pied-piping to pass in a similar fashion to that presented for complements of know and surprise-type predicates, make echo questions follow a derivation similar to that in (24).

While it is beyond the scope of this paper, the above analysis could also be applied to massive pied-piping in relative clauses. If it were also assumed that relative clauses bear a similar split CP-structure to that presented above and that $\mathrm{C}$ lacked a feature [wH], it may also be able to account for the availability of massive pied-piping in relative clause, both nonrestrictive and restrictive. Additional research is necessary to see if this analysis can apply to massive pied-piping constructions in a broader context, ranging from pied-piping of a preposition following (following Cable \& Harris 2011) to pied-piping of a larger VP.

5. Conclusion. In this paper, I have shown that Heck's $(2004$; 2008) generalization on massive pied-piping cannot fully account for the full distribution of where this marked construction can occur. By revising his analysis to focus on the non-interrogative nature of the $\mathrm{CP}$ hosts that allow massive pied-piping, we can incorporate the two-stage $w h$-agreement process argued for by Den Dikken (2003) into the Q-movement analysis proposed by Cable (2010). 


\section{References}

Cable, Seth. 2010. The grammar of Q: Q-particles, wh-movement, and pied-piping. Oxford: Oxford University Press.

Cable, Seth \& Jesse A. Harris. 2011. On the grammatical status of PP-pied-piping in English: Results from sentence-rating experiments. In Jesse A. Harris \& Margaret Grant (eds.), University of Massachusetts occasional papers in linguistics: Processing linguistic structure, vol. 38. 1-22. Amherst, MA: GLSA Publications.

Corver, Norbert. 2017. Freezing effects. In Martin Everaert \& Henk C. van Riemsdijk (eds.), The Wiley Blackwell companion to syntax, vol. 2. 1711-1743. Malden, MA: WileyBlackwell.

Dikken, Marcel den. 2003. On the morphosyntax of wh-movement. In Cedric Boeckx \& Kleanthes K. Grohmann (eds.), Multiple wh-fronting, vol. 64. 77. Amsterdam: John Benjamins Publishing.

Dikken, Marcel den \& Anastasia Giannakidou. 2002. From hell to polarity: "Aggressively non-D-linked" wh-phrases as polarity items. Linguistic Inquiry 33(1). 31-61. https://doi.org/10.1162/002438902317382170.

Emonds, Joseph. 1979. Appositive relatives have no properties. Linguistic Inquiry 10(2). 211243.

Grimshaw, Jane. 1979. Complement selection and the lexicon. Linguistic Inquiry 10(2). 279326.

Heck, Fabian. 2004. A theory of pied-piping. Tübingen: Universität Tübingen dissertation.

Heck, Fabian. 2008. On pied-piping: Wh-movement and beyond. Berlin \& New York: Mouton de Gruyter.

Huddleston, Rodney D. \& Geoffrey K. Pullum. 2002. The Cambridge grammar of the English language. Cambridge \& New York: Cambridge University Press.

Richards, Norvin. 2016. Contiguity theory. Cambridge, MA: MIT Press.

Richards, Norvin. 2017. Contiguity theory and pied-piping. http://ling.auf.netlingbuzz/003288.

Ross, John Robert. 1967. Constraints on variables in syntax. Cambridge, MA: MIT dissertation.

Ross, John Robert. 1986. Infinite syntax! Norwood, N.J: ABLEX.

Stockwell, Robert P., Paul Schacter \& Barbara Hall Partee. 1973. The major syntactic structures of English. New York: Holt, Rinehart and Winston. 